\title{
XAS Study on Electron Transfer in Cobalt Complexes Containing Catecholate and Semiquinone Ligands
}

\author{
J.-C. Park, D.-K. Kim*, O.-S. Jung** and J.-H. Choy*** \\ Department of Chemistry, Pusan Women's University, Pusan 617-736, Korea \\ * Department of Chemistry, Kyungpook National University, Taegu 702-701, Korea \\ ** Inorganic Chemistry Laboratory, KIST, Seoul 136-791, Korea \\ *** Department of Chemistry, Center for Molecular Catalysis (CMC), Seoul National University, \\ Seoul 151-742, Korea
}

\begin{abstract}
XAFS measurements have been carried out at both room temperature and $100 \mathrm{~K}$ on complexes of general form of $\mathrm{Co}^{\mathrm{III}}(\mathrm{N}-\mathrm{N})(\mathrm{DBQ})$, where $\mathrm{N}-\mathrm{N}$ is 1,10-phenanthroline(phen), $N, N, N^{\prime}, N^{\prime}$-tetramethylethlenediammine(tmeda), and $\mathrm{DBQ}$ is the 3,6di-tert-butylcatechol or 3,6-di-tert-semiquinone ligands. Co K-edge XAFS spectra disclosed that Co(tmeda)(DBQ) ${ }_{2}$ is locked in a charge distribution of $\mathrm{Co}^{\mathrm{III}}$ (tmeda)(3,6-DBSQ)(3,6-DBCat), while $\mathrm{Co}(\mathrm{phen})(\mathrm{DBQ})_{2}$ is accompanied by the transition of $\mathrm{Co}^{\mathrm{III}} / \mathrm{Co}^{\mathrm{II}}$ dependent on temperature.
\end{abstract}

\section{INTRODUCTION}

Transition metal complexes containing quinone ligands have been shown to have metal- and quinone-localized electronic levels that are close in energy.[1] As a consequence, intramolecular charge transfer between metal and ligand occurs at low energy, and, in some cases, under conditions of thermal equilibrium.[2,3] Structural changes that accompany shifts in metal oxidation state have been applied to materials that exhibit photomechanical properties and optical switching effects.[4] The most extensively studied equilibria of this type occur for complexes of cobalt of general formula $\mathrm{Co}(\mathrm{N}-\mathrm{N})(\mathrm{DBQ})_{2}$, where $\mathrm{DBQ}$ is the semiquinone or catecholate form of either 3,5- or 3,6-di-tert-butyl-1,2-benzoquinone and $\mathrm{N}-\mathrm{N}$ is a bidentate nitrogen-donor coligand. Temperature - dependent equilibria (eq. 1) may be observed in the solid state as well as in solution by monitoring

$$
\mathrm{Co}^{\mathrm{II}}(\mathrm{N}-\mathrm{N})(\mathrm{DBSQ})(\mathrm{DBCat}) \leftrightarrow \mathrm{Co}^{\mathrm{I}}(\mathrm{N}-\mathrm{N})(\mathrm{DBSQ})_{2}
$$

changes in either optical spectrum or magnetism with the shift from low-spin Co ${ }^{\text {III }}$ to high-spin Co ${ }^{\text {II }}$. Although the spectroscopic studies on the transition of oxidation state have been elucidated for both solution and the solid state, the direct measurements of the structural changes associated with the transition of oxidation state have been limited to crystalline samples. In this respect, $\mathrm{X}$-ray absorption spectroscopy has become a powerful tool for probing both electronic and geometric structures for any types of samples.[5] In this paper, XAFS studies are established on two cobalt complexes [Co(tmeda)(3,6-DBQ) 2 (sample A) and $\mathrm{Co}($ phen $)(3,6-\mathrm{DBQ})_{2}$ (sample B)] in crystalline state, which will be applicable to compounds in noncrystalline states such as polymer or solution samples.

\section{EXPERIMENTAL}

Synthetic procedures to form the title complexes followed the previously reported ones.[2] The XAFS spectra at the cobalt Kedge were recorded on beam line $10 \mathrm{~B}$ of the Photon Factory in the transmission mode at room temperature and $100 \mathrm{~K}$. For XAFS spectra, a linear background was subtracted from the experimental spectra by extrapolating the least-square fitting of the pre-edge experimental points, and the edge jump was set to unity. In order to determine the structural parameters, a curve fitting was performed with the UWXAFS code[6] for the first shell in the Fourier transform (FT), using theoretical functions calculated by the FEFF 5 code[7] for all scattering paths.

\section{RESULTS AND DISCUSSION}

Fig. 1 shows the Co K-edge XANES spectra recorded at both room temperature and $100 \mathrm{~K}$ for the present compounds. Sample $\mathrm{B}$ shows an overall spectral shift of about $1.5 \mathrm{eV}$ to a higher energy side at $100 \mathrm{~K}$, while sample A shows the same spectra irrespective of temperature. These spectral changes indicate that sample B undergoes the oxidation state transition of $\mathrm{Co}^{I I} \rightarrow$ $\mathrm{CO}^{\mathrm{II}}$ such as eq. (1) due to electron transfer from metal to ligand as the temperature decreases. These results are in good agreement with the fact that the transition temperature of eq. (1) is $410 \mathrm{~K}$ and $250 \mathrm{~K}$ for sample A and sample B, respectively. FTs of the Co K-edge EXAFS spectra in Fig. 2 represent the same pattern as XANES spectra. That is, FTs for sample A are almost the same at both temperatures, but room temperature FT of sample B is completely different from low temperature FT. Especially, the shape of first-shell peak, which is due to $\mathrm{N}$ and $\mathrm{O}$ backscatters around cobalt atom, indicates that the local symmetry on $\mathrm{Co}^{\text {III }}$ ions is almost octahedral, but $\mathrm{Co}^{\text {II }}$ ions have lower local symmetry. The Fourier filtered spectra of the firstshell peak and the best fits are shown in Fig. 3, and the fitted structural parameters are summarized in Table 1. Bond distances between cobalt and $\mathrm{N} / \mathrm{O}$ atoms fitted for sample $\mathrm{A}$ are consistent with those $\left(\mathrm{d}\left(\mathrm{Co}-\mathrm{O}_{\mathrm{av}}\right)=1.872 \AA ; \mathrm{d}\left(\mathrm{Co}-\mathrm{N}_{\mathrm{av}}\right)=2.026 \AA\right)$ determined by means of single crystal X-ray diffraction at RT.[2] In addition, Co-N/O bond distances of sample A are very similar to those of sample $\mathrm{A}$ at low temperature, in which $\mathrm{Co}$ in ions are stabilized. On the other hand, sample $\mathrm{B}$ at $\mathrm{RT}$ was not 


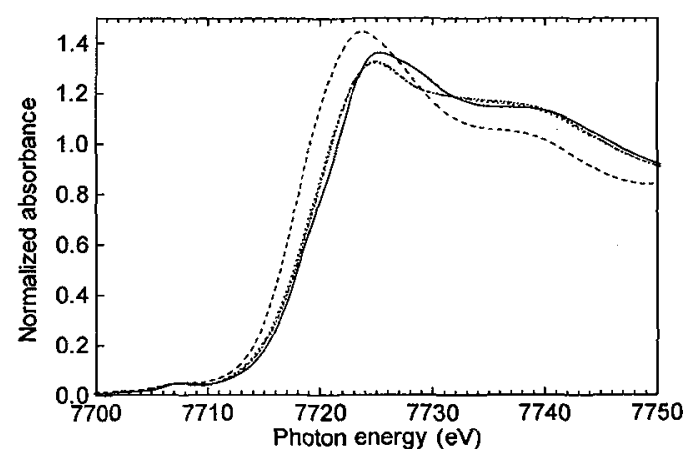

Figure 1: Co K-edge XANES spectra for sample A (RT;---, 100K;.-) and sample B (RT;----, 100K;--).
Table 1. Curve-fitting Results for Co K-edge EXAFS.

\begin{tabular}{cccccc}
\hline sample & shell & $N^{\mathrm{a}}$ & $R(\AA)^{\mathrm{a}}$ & $\sigma^{2}\left(\AA^{2}\right)^{\mathrm{a}}$ & $\Delta E_{0}(\mathrm{eV})^{\mathrm{a}}$ \\
\hline A & Co-N & 2.0 & 2.03 & 0.0066 & -13.7 \\
(RT) & Co-O & 3.7 & 1.86 & 0.0038 & -12.9 \\
B & Co-N & 1.0 & 2.03 & 0.0052 & -22.9 \\
$(100 \mathrm{~K})$ & Co-O & 4.2 & 1.87 & 0.0029 & -16.8 \\
B & Co-N & 2.1 & 2.15 & 0.0111 & -7.7 \\
(RT) & Co-O & 2.2 & 2.06 & 0.0059 & 0.2 \\
& Co-O & 2.2 & 1.90 & 0.0034 & 0.2 \\
\hline
\end{tabular}

$\mathrm{N}$ is the number of scatterers. $R$ is the metal-scatterer distance. $\sigma^{2}$ is a mean square deviation in $R, \Delta E_{0}$ is the shift in $E_{0}$ for the theoretical scattering function.

only well fitted with the addition of a third backscattering term but also presents larger bond distances Co-N/O, which is due to the presence of $\mathrm{Co}^{\mathrm{I}}$ ions. From the comparison of the bond distances of sample $\mathrm{B}$ at RT with those $\left(\mathrm{d}\left(\mathrm{Co}-\mathrm{O}_{\mathrm{av}}\right)=2.066 \AA\right.$ and $\left.\mathrm{d}\left(\mathrm{Co}-\mathrm{N}_{\mathrm{av}}\right)=2.165 \AA\right)$ of another $\mathrm{Co}^{\mathrm{I}}$-complex, $\mathrm{Co}^{\mathrm{II}}\left(\mathrm{NO}_{2}\right.$-phen $)(3,6-\mathrm{DBSQ})_{2}$ [8], suggest that the local symmetry around $\mathrm{Co}$ ions is changed from octahedral structure to trigonal prismatic one with the transition of $\mathrm{Co}^{\text {III }} \rightarrow \mathrm{Co}^{\mathrm{II}}$.

\section{Conclusion}

The present temperature-dependent XAFS studies for cobalt semiquinonate/catecholate complexes have shown that the ligandto metal charge transfer results in the $\mathrm{Co}^{\mathrm{II}} / \mathrm{Co}^{\mathrm{I}}$ transition and accompanying local structural change. XAFS is also expected to give a useful information on temperature-dependent electronic and structural changes of tautomeric forms of complex in polymer state that is industrially potential due to their photochemical properties and optical switching effects.

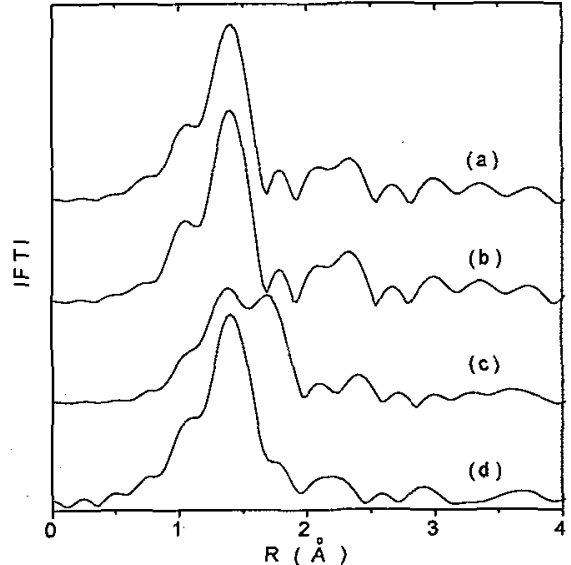

Figure 2: FTs of Co K-edge EXAFS for sample $A$ at RT (a) and $100 \mathrm{~K}$ (b), and sample B at RT (c) and $100 \mathrm{~K}$ (d)

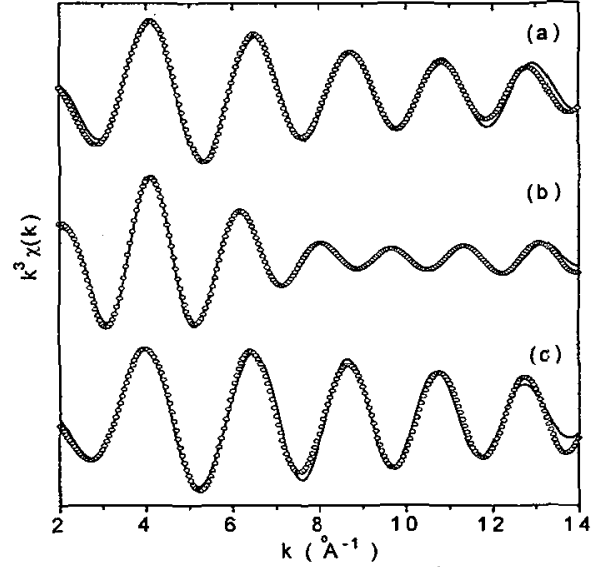

Figure 3: Experimental Fourier filtered $k^{3} \chi(k)(O)$ of the first peak in FTs and the best fits $(-)$ for sample A at RT (a), sample B at $\mathrm{RT}(\mathrm{b})$ and $100 \mathrm{~K}(\mathrm{c})$.

\section{Acknowdelgments}

The authors are grateful to Prof. M. Nomura (PF, Japan) for his help in obtaining XANES spectra (Proposal No. 94G21 1).

\section{References}

[1] Pierpont C. G., Lange C. W., Prog. Inorg. Chem. 41 (1993) 381.

[2] Jung O. -S., Pierpont C. G., Inorg. Chem. 33 (1994) 2227.

[3] Attia A. S., Pierpont C. G., Inorg. Chem. 34 (1995) 1172.

[4] Jung O. -S., Pierpont C. G., J. Am. Chem. Soc. 116(1994) 2229.

[5] Choy J. -H, Yoon J. -B, Kim D. -K, Hwang S. -H, Inorg. Chem. 34 (1995) 6524.

[6] Newville M.,Livins P., Yocoby Y., Rehr J. J., Stern E. A., Phys. Rev, B 47 (1993) 14126.

[7] Rehr J. J., Mustre de Leon J., Zabinsky S. I., Albers R. C., J. Am. Chem. Soc. 113 (1991) 5135.

[8] Jung O. -S, Pierpont C. G., J. Am. Chem. Soc. 116 (1994) 1127. 